\title{
Attitudes toward disaster-prevention risk in Japanese coastal areas: analysis of civil preference
}

\author{
Kohei Imamura ${ }^{1}$ Kohei Takenaka Takano ${ }^{1}$. \\ Nobuhito Mori $^{2} \cdot$ Tohru Nakashizuka ${ }^{1} \cdot$ Shunsuke Managi $^{3}$
}

Received: 14 October 2015/Accepted: 23 January 2016/Published online: 18 February 2016

(C) The Author(s) 2016. This article is published with open access at Springerlink.com

\begin{abstract}
Facing potential coastal disasters such as storm surges, storm waves, and tsunamis, Japan has planned the construction of coastal structures such as seawalls or breakwaters along its coastal areas. However, some conflicts exist among the public whether such constructions should be undertaken or whether the natural coast should be conserved. This study uses a choice experiment to investigate opinions of coastal citizens about (1) the acceptable loss of coastal wildlife species as a tradeoff for seawalls; (2) the willingness to pay (WTP) for conservation of coastal wildlife as a compromise for disaster risk reduction; (3) the influence on popular preferences in coastal management of individual characteristics, such as frequency of visiting the sea and public recognition of disaster risk; and (4) civil trust in scientific information. The survey was conducted among 7496 respondents in municipalities around the Japanese coast. As a result, the acceptable loss of coastal wildlife species was $18.7 \%$. The marginal WTP for conserving the coastal wildlife was 680.95 JPY per percent in the number of species per capita. We found that people who frequently visit the sea preferred ecosystem conservation and disliked seawall construction, whereas people strongly recognizing disaster risks preferred seawall construction. Furthermore, we found that civil trust in scientific information affects civil preferences regarding coastal management. Our study indicates the need to reduce negative effects of coastal constructions on coastal ecosystems and to consider other options, such as ecosystem-based disaster risk reduction. It also indicates the social influences of raising
\end{abstract}

Kohei Imamura

pbilvowxwovlidq@yahoo.co.jp

Shunsuke Managi

managi@doc.kyushu-u.ac.jp

1 Graduate School of Life Sciences, Tohoku University, 6-3 Aoba, Aramaki-Aza Aoba, Aoba-Ku, Sendai 980-8578, Japan

2 Disaster Prevention Research Institute, Kyoto University, Gokasho, Uji, Kyoto 611-0011, Japan

3 Urban Institute, Departments of Urban and Environmental Engineering, School of Engineering, Kyushu University, 744 Motooka, Nishi-Ku, Fukuoka 819-0395, Japan 
public trust in scientific information to enable citizens to make better decisions regarding coastal management.

Keywords Coastal disaster - Seawall · Coastal species · 2011 Tohoku earthquake · Choice experiment

\section{Introduction}

Coastal structures (seawalls or breakwaters) mitigate coastal disasters such as storm surges, storm waves, and tsunamis, although their construction may have large negative ecological effects on coastal ecosystems (Lindsay et al. 1992; Toft 2005; Dugan et al. 2008). Protecting human lives and property from coastal disasters is important; however, coastal ecosystem services offer a range of benefits that have been increasingly recognized for centuries because of the rapid decrease in coastal ecosystems (Millennium Ecosystem Assessment 2005). When making decisions regarding the tradeoff between reducing coastal disasters and conserving coastal ecosystems, it is essential to understand public preferences regarding the options available in coastal management policies.

The Japanese government recently began constructing seawalls along some coastlines based on the risk of tsunamis from predicted earthquakes with high magnitudes (Earthquake Research Committee 2014), storm waves, and storm surges enhanced by climate change (e.g., Mori et al. 2010; Yasuda et al. 2014). For example, the construction of 14.6$\mathrm{m}$-high seawalls is planned for the Motoyoshi coast, which was heavily damaged by a tsunami during the 2011 Tohoku earthquake in the Miyagi prefecture [The Nature Conservation Society of Japan (NACS-J) 2013]. Construction of high seawalls is also planned in other municipalities that were not damaged by the tsunami during the 2011 Tohoku earthquake (e.g., the Naga coast in Tokushima prefecture) (NACS-J 2013). These high seawalls require wide foundations. NACS-J (2013) noted that the foundation of a 10-mhigh seawall would be $40 \mathrm{~m}$ wide. It is obvious that the construction of seawalls with such wide foundations would greatly deteriorate coastal ecosystems. Consequently, serious debates emerged regarding the tradeoff between constructing such high seawalls and conserving coastal ecosystems. Therefore, it is necessary to understand popular preferences before making difficult decisions regarding the tradeoff between constructing seawalls or conserving coastal ecosystems. Tsunamis have huge and negative impacts on land-based ecosystem (e.g., Urabe et al. 2013). Construction of seawalls leads preventing ecosystem damages by tsunamis. Ecosystems damaged by tsunamis, however, recover relatively quickly over time in some cases (Nakashizuka 2013). Murakami et al. (2013) reported that recorded biodiversity even enhanced after the tsunami. On the other hand, ecosystems destroyed by construction of a seawall will not recover as long as the seawalls exist. We use "the tradeoff between constructing seawalls and conserving coastal ecosystems" in this context from long-term perspectives.

The concept of ecosystem-based disaster risk reduction (Eco-DRR) has recently begun to attract more attention (Gupta and Nair 2012). The 2004 Indian Ocean tsunami triggered global interest in promoting ecosystem-based approaches for reducing disaster risks, causing increased international attention on the role of coastal ecosystems as natural shields against coastal hazards (Estrella and Saalismaa 2012). Well-managed ecosystems can provide natural protection against common natural hazards, such as landslides, flooding, avalanches, storm surges, wildfires, and droughts (Dolidon et al. 2009; Estrella 
and Saalismaa 2012). Coastal ecosystems can reduce physical exposure of inland areas to natural hazards by serving as natural protective barriers or buffers, thus mitigating hazard effects (Estrella and Saalismaa 2012; Gonzalez and Marques 2008; Granek and Ruttenberg 2007; Government of Sri Lanka et al. 2011; Government of Sri Lanka and Disaster Management Centre 2005; Hanley and Barbier 2009). Estrella and Saalismaa (2012) point out "The Intergovernmental Oceanographic Commission (IOC) recommends harnessing the potential of various coastal ecosystems-e.g., coral reefs, sand dunes, and coastal vegetation-for coastal protection." This approach acknowledges the importance and cost effectiveness of natural infrastructure in mitigating lower-magnitude coastal hazards (i.e., storm waves) and advocates multiple uses of coastal zones. Estrella and Saalismaa (2012) also points out that "Maintaining and restoring ecosystems as natural (or green) infrastructures can offer high benefit-cost ratios compared to engineered infrastructures; however, natural buffers may not always be feasible due to an incalculable disaster reduction function, natural variability, biological limitations, space constraints, incompatibility with priority land uses, and prohibitive costs." In such cases, hard infrastructures may be required to provide necessary protection (Estrella and Saalismaa 2012). A hybrid approach combining natural (i.e., sand dunes, coastal forests) and hard defenses may be also most effective (Estrella and Saalismaa 2012). By estimating public preferences regarding constructing coastal infrastructures and conserving coastal ecosystems, we can clarify the potential of incorporating Eco-DRR in Japanese coastal management. If citizens prefer to avoid ecosystem degradation in exchange for constructing coastal infrastructures, EcoDRR offers a valuable option.

Scientific information may play an important role in decision making. Current coastal management plans in Japan are based on scientific projections of the likelihood of tsunamis, storm waves, and storm surges (e.g., Earthquake Research Committee of Japan 2014; Mori et al. 2010; Yasuda et al. 2014). Public preferences regarding coastal management are thus likely to be affected by whether coastal citizens trust scientific information of potential coastal disasters. Previous studies have analyzed the relation between public preferences regarding environmental policies and civil trust in scientific information, especially in the area of climate change (e.g., Akter et al. 2012; Poortinga et al. 2011; Lee and Cameron 2008; Carson et al. 2010; Akter and Bennett 2011; Cameron 2005; Viscusi and Zeckhauser 2006). Akter et al. (2012) investigated the influence of climate change skepticism on preferences for climate change mitigation in Australia and found that skepticism regarding causes and mitigation measures played significant roles in determining popular support for climate change abatement. However, for topics such as ecosystem degradation and earthquakes, the influence of civil trust in scientific information on civil preferences for environmental policies has not been investigated. When considering potential management options in Japanese coastal areas, it is important to investigate influences of public trust in scientific information about ecosystem degradation, climate change, and earthquake occurrence.

This study investigates (1) the acceptable loss of coastal wildlife species when raising seawall heights, (2) the public's willingness to pay (WTP) for the conservation of coastal wildlife, (3) the influences of the frequency of visiting the sea and the popular recognition of the possibility of suffering potential personal damages due to coastal disasters, and (4) the influences of public trust in scientific information on ecosystem degradation, climate change, and earthquakes upon civil preferences for coastal management. We investigated the influences of the frequency of visiting the sea following Tsurumi and Managi (2015) where the frequency of visiting target area was analyzed as a key explanatory variable. Clarifying these values will inform a discussion of the possibility of implementing Eco- 
DRR in Japanese coastal areas as well as the role of coastal management in terms of civil trust in scientific information.

\section{Methods}

\subsection{Survey design}

We conducted a choice experiment by providing respondents with the following hypothetical situation:

1. The respondent's municipal government is planning to raise seawalls to enhance disaster prevention in coastal areas.

2. However, an environmental assessment revealed that coastal wildlife would be lost due to seawall construction.

3. The government is therefore considering setting up a coastal wildlife conservation fund to reduce the negative effects of the seawall, with the money to be raised by donations from residents.

4. In addition, the government is also considering another option for disaster risk reduction: providing governmental subsidies for residents to move to disaster-free areas.

After providing the hypothetical situation, we provided respondents with eight different scenario sets. Each scenario set comprised three different coastal scenarios: alternative scenarios 1 and 2 and a business-as-usual (BAU) scenario (Fig. 1). The BAU scenario only

\begin{tabular}{|c|c|c|c|}
\hline & $\begin{array}{l}\text { Alternative } \\
\text { Scenario } 1\end{array}$ & $\begin{array}{l}\text { Alternative } \\
\text { Scenario } 2\end{array}$ & $\begin{array}{l}\text { The original } \\
\text { scenario }\end{array}$ \\
\hline The number of coastal species & $60 \%$ decrease & Not change & $100 \%$ decrease \\
\hline $\begin{array}{l}\text { The monetary benefits from } \\
\text { coastal ecosystem services }\end{array}$ & $40 \%$ decrease & Not change & $100 \%$ decrease \\
\hline The raising height of the seawall & $1 \mathrm{~m}$ & $2 m$ & $3 m$ \\
\hline $\begin{array}{l}\text { The subsidy rate in the moving } \\
\text { costs }\end{array}$ & $100 \%$ & $40 \%$ & $0 \%$ \\
\hline $\begin{array}{l}\text { The monetary donation for } \\
\text { ecosystem conservation }\end{array}$ & $1000 \mathrm{JPY}$ & $3000 \mathrm{JPY}$ & O JPY \\
\hline & $\downarrow$ & $\downarrow$ & $\downarrow$ \\
\hline $\begin{array}{l}\text { Q1 } \\
\text { Please choose a preferable } \\
\text { scenario for you. }\end{array}$ & $\square$ & $\square$ & $\square$ \\
\hline $\begin{array}{l}\text { Q2 } \\
\text { Would you like to move } \\
\text { properties? }\end{array}$ & $\begin{array}{l}\square \text { Yes } \\
\square \text { Neither or not } \\
\square \text { No }\end{array}$ & $\begin{array}{l}\square \text { Yes } \\
\square \text { Neither or not } \\
\square \text { No }\end{array}$ & \\
\hline
\end{tabular}

Fig. 1 Sample scenario set 
involves raising the seawall, meaning that the coastal ecosystem would disappear entirely. Alternative scenarios 1 and 2 included not only increasing the seawall heights but also conserving the ecosystem or having residents move away from the area. Each scenario included five attributes: (a) the decline in the number of coastal wildlife species after conducting the scenario; and (b) the decrease in the monetary benefits from ecosystem services after conducting the scenario; (c) the amount by which the seawall was raised; (d) the subsidy rate for moving (i.e., ratio of government subsidies to total moving costs); (e) the amount of monetary donations required for ecosystem conservation (Fig. 1). The attribute "monetary benefits from ecosystem services" was explained as "benefit from use of coastal wildlife" in the questionnaire. Each scenario in a scenario set had different levels of these attributes. Respondents were asked to (1) choose one scenarios that represented a preferable measure for coastal disaster prevention (Q1 of Fig. 1) and (2) answer their willingness to move (WTM) (yes, neither yes or no, or no) under alternative scenarios 1 and 2 (Q2 of Fig. 1).

The eight scenario sets in the questionnaire varied by the levels of the variables across alternative scenarios 1 and 2. Alternative scenarios 1 and 2 were generated by a random combination with prearranged levels for each attribute (Table 1). The levels of the raising height of the seawall were based on the actual height being planned by Japanese government and municipalities. Contrary to the raising height of the seawall, the original height of seawall, or status-quo, largely differs among areas. Therefore, we did not provide the information about the original heights of seawalls to respondents. The levels of the donation for coastal ecosystem conservation activities were set following the levels in the previous study (Shoyama et al. 2013). "The number of coastal species" and "the monetary benefits from coastal ecosystem services" are relative values compared to BAU. The BAU scenario was fixed to a single condition in which the seawall height would be raised by $3 \mathrm{~m}$ and coastal wildlife and monetary benefits from ecosystem services would entirely disappear (100\% decrease) (Fig. 1). We generated 100 combinations of levels in alternative scenarios 1 and 2. In generating the versions, unrealistic combinations of the attributes (i.e., $100 \%$ decrease in coastal wildlife and no change in ecosystem services) were removed. Each respondent's version was randomly determined from these 100 versions.

\subsection{Data collection}

This study's survey was conducted over the Internet between January 29, 2014 and February 5, 2014. The study areas were all municipalities along the Pacific Ocean and the Inland Sea of Japan. Nikkei Research Inc. conducted the internet survey using already existing panel. Men and women from 20 to 69 years old were randomly selected along actual ratio of Japanese population for gender, age (i.e., 20s, 30s, 40s, 50s, and 60s).

Table 1 Attributes and levels of coastal future scenarios

\begin{tabular}{ll}
\hline Attributes & Levels \\
\hline The number of coastal species & $-0,-20,-40,-60,-80,-100 \%$ \\
The monetary benefits from coastal ecosystem services & $-0,-20,-40,-60,-80,-100 \%$ \\
The raising height of the seawall & $0,1,2,3 \mathrm{~m}$ \\
The subsidy rate in the moving costs & $0,20,40,60,80,100 \%$ \\
The donation for coastal ecosystem conservation activities & $¥ 0, ¥ 100, ¥ 1000, ¥ 2000, ¥ 5000$, \\
& $¥ 10,000, ¥ 50,000$
\end{tabular}


Consequently, 7496 valid responses were obtained. A summary of the respondents' characteristics is shown in Table 5 of the "Appendix" file.

The survey was constructed as follows. The first section of the questionnaire asked about respondents' trust in scientific information about ecosystem degradation, climate change, and earthquakes. The second section asked about respondents' experiences with past storm surges or tsunamis and their recognition of the potential for storm surges or tsunamis. The answers for the questions in the first and second sections are shown in Table 6 of the "Appendix" file. The third section presented the scenario sets. The fourth section asked about the respondents' socioeconomic characteristics.

\subsection{Analysis}

We conducted three types of analyses: (1) estimation of preferences for different scenario attributes; (2) estimation of the effect of respondents' characteristics on their preferences for the scenario attributes; and (3) estimation of the effects of respondents' characteristics on WTM. The first analysis corresponds to purposes 1 and 2 of this study. In the first analysis, we estimated the acceptable loss in terms of coastal wildlife species numbers as a result of raising seawall heights and the WTP for the conservation of coastal wildlife. The second and third analyses correspond to purposes 3 and 4 of this study and estimate the influences of frequency of visiting the sea, public recognition of the possibility of suffering personal damages as a result of coastal disasters, and public trust in scientific information about ecosystem degradation, climate change, and earthquakes on popular preferences regarding coastal management.

The first analysis estimated the model representing the effects of scenario attributes on the likelihood of choosing a particular scenario. The dependent variable is a dummy variable representing respondent's answers for question Q1 in Fig. 1. The explanatory variables are scenario attributes such as alternative-specific constants $(A S C)$, height of seawall rise (Seawall), subsidy rate for moving costs (Subsidies), amount of monetary donations required for ecosystem conservation (Donation), rate of decline in the number of coastal wildlife species after conducting the scenario (Species), and decrease in monetary benefits from ecosystem services after conducting the scenario (Services). We divided ASC into $A S C 1$ and $A S C 2$ for removing an effect of position of scenario on the questionnaire (i.e., left, middle, or right) and to increase accuracy in estimation of the other parameters. The effect of a position means the effects of a phenomenon where a respondent always chooses scenarios of the same position (left, middle, or right) irrespective of the scenario attributes. The effect of a position can bias the estimation of parameters. Estimation methods are the generalized multinomial logit (GMNL) model in preference space (Fiebig et al. 2010, Greene and Hensher 2010). We did not constraint the gamma parameter in the GMNL in preference space. We assumed that coefficients on all explanatory variables are normally distributed. We calculated the preference score (PS) by multiplying the coefficients by specific levels of the scenario attributes. The PS is determined as follows:

$$
\begin{aligned}
\mathrm{PS}= & (\text { ASC } 1 \text { or ASC } 2)+\beta_{1} \text { Seawall }+\beta_{2} \text { Subsidies }+\beta_{3} \text { Donation }+\beta_{4} \text { Species } \\
& +\beta_{5} \text { Services }
\end{aligned}
$$

where the $\beta_{1}, \beta_{2}, \beta_{3}, \beta_{4}$, and $\beta_{5}$ are the coefficients provided by the analysis using the preference-space GMNL. The PS indicates a respondent's degree of preference for the scenario. A scenario showing high PS is preferred, and it tends to be chosen. The PS of the scenario in which nothing changes (no seawall height increases, no ecosystem 
conservation, and no moving to a new area) is $A S C 1$ or $A S C 2$. The acceptable loss of coastal wildlife species numbers can be determined by regarding Eq. (1) as a first-degree polynomial function of one variable. In other words, we considered the following equation derived from Eq. (1).

$$
\mathrm{PS}=\beta_{4} \text { Species }+(\text { ASC1 or ASC } 2)+3 \beta_{1}
$$

Equation (2) is the specific case of Eq. (1) when Seawall is three meters (max height of seawall height increases) and Subsidies, Donation, and Services are 0. Equation (2) also represents a condition where ecosystem conservation and moving to a new area are not conducted, while the monetary benefits from ecosystem services do not change by seawall height increases. In Eq. (2), the value of Species, when the value of PS is equivalent to that of PS of a scenario where nothing changes (i.e., ASC1 or ASC2), is regarded as the acceptable loss of wildlife species. In addition, the WTP for conserving coastal wildlife can be calculated using the following equation derived from Eq. (1):

$$
\text { Donation }=-\beta_{4} / \beta_{3} \text { Species }+K
$$

where $K$ is a constant decided by the values of PS, ASC1 or ASC2, Seawall, Subsidies, and Services. The $-\beta_{4} / \beta_{3}$ is the marginal WTP for coastal wildlife. The $-\beta_{4} / \beta_{3}$ cannot be calculated from the analysis using the preference-space GMNL because of the rather arbitrary choice of distribution that arises from dividing the coefficients of the nonmonetary attributes by the monetary coefficient (Hole and Kolstad 2012). To avoid this problem, we also conducted the analysis using WTP-space GMNL, which is a type of GMNL that directly estimates ratios of attribute coefficients to a monetary coefficient. WTP-space GMNL was developed by Fiebig et al. (2010), Greene and Hensher (2010), Train (2009), and Thiene and Scarpa (2009). Few studies have used WTP-space analysis, whereas Train and Weeks (2005), Sonnier et al. (2007), Scarpa et al. (2008), and Hole and Kolstad (2012) used evaluation methods. In this study, we used preference-space GMNL to estimate the acceptable loss of coastal wildlife species as a result of raising seawall heights, and we used WTP-space GMNL to estimate the marginal WTP for conserving coastal wildlife. We constrained the gamma parameter to be 0 in the GMNL in WTP space following the previous studies. This type of the GMNL is called "GMNL-II" (Fiebig et al. 2010).

The second analysis estimated the model representing the effect of the respondents' characteristics on their scenario attribute preferences. This model is generated by adding interaction terms between scenario attributes and respondent characteristics to the explanatory variables from the first analysis. The respondents' characteristics used in this analysis are shown in Table 7 in the "Appendix". The estimation method is the scale heterogeneity multinomial logit model (S-MNL) in preference space. The second analysis clarified the influences of visiting frequency to sea, public recognition of the potential for suffering personal damages from coastal disasters, and public trust in scientific information about ecosystem degradation, climate change, and earthquakes.

The third analysis estimated the model representing the effect of respondents' characteristics on their WTM. The dependent variable is the ordered variable representing respondents' answers to Q2 of Fig. 1. The explanatory variables are the scenario attributes and the respondents' characteristics (Table 7 in the "Appendix"). We estimated the model using the random-effects ordered logistic regression model. The third analysis clarified the influences on civil WTM of frequency of visiting the sea, public recognition of potentially suffering personal damages due to coastal disasters, and public trust in scientific information about ecosystem degradation, climate change, and earthquakes. In particular, we 
focused on the extent to which the probability of a "yes" WTM increased with changes in respondents' characteristics.

All explanatory variables are summarized in Table 7 in the "Appendix". All analysis considered the data as panel. Halton sequences were chosen as the simulation method. The number of replications was set to 500. Correlation among random parameters was not allowed. Statistical analysis was conducted with the statistical software Stata 13. We used the commands of GMNL developed by Gu et al. (2013). The command of the randomeffects ordered logistic regression is a preset command of Stata 13.

\section{Results}

\subsection{Effects of scenario attributes}

Table 2 represents the estimation result of the simple model. Mean in Table 2 is core results representing civil preferences. Standard deviation in Table 2 represents residual preference heterogeneity relative to scale heterogeneity ( $\mathrm{Gu}$ et al. 2013). ASC1 and ASC2 had significantly positive effects on the probability of a respondent choosing a particular scenario (Model 1 of Table 2). The values of coefficients of ASC2 were approximately

Table 2 Estimation results of the simple models

\begin{tabular}{|c|c|c|c|c|}
\hline \multirow[t]{2}{*}{ Variables } & \multicolumn{2}{|c|}{ Model 1 (preference space) } & \multicolumn{2}{|c|}{ Model 2 (WTP space) } \\
\hline & Coefficients & SE & Coefficients & SE \\
\hline \multicolumn{5}{|l|}{ Mean } \\
\hline$A S C 1$ & $0.67 * * *$ & 0.05 & $12,747.26 * * *$ & 1022.68 \\
\hline$A S C 2$ & $1.11 * * *$ & 0.05 & $24,465.53 * * *$ & 1074.77 \\
\hline Species & $2.8 \mathrm{E}-02 * * *$ & $8.0 \mathrm{E}-04$ & $680.95 * * *$ & 17.80 \\
\hline Services & $1.4 \mathrm{E}-02 * * *$ & $4.2 \mathrm{E}-04$ & $316.22 * * *$ & 10.01 \\
\hline Seawall & $0.18 * * *$ & $1.6 \mathrm{E}-02$ & $3874.74 * * *$ & 373.75 \\
\hline Subsidies & $9.8 \mathrm{E}-03 * * *$ & $4.2 \mathrm{E}-04$ & $229.98 * * *$ & $1.0 \mathrm{E}-04$ \\
\hline Donation & $-5.9 \mathrm{E}-05 * * *$ & $2.0 \mathrm{E}-06$ & 1 & (Constraint) \\
\hline \multicolumn{5}{|l|}{ Standard deviation } \\
\hline$A S C 1$ & $-1.10 * * *$ & 0.05 & $-23,361.10 * * *$ & 1034.92 \\
\hline$A S C 2$ & $1.35 * * *$ & 0.04 & $-29,446.92 * * *$ & 874.91 \\
\hline Species & $0.04 * * *$ & $1.1 \mathrm{E}-03$ & $881.36 * * *$ & 20.92 \\
\hline Services & $0.02 * * *$ & $7.6 \mathrm{E}-04$ & $420.47 * * *$ & 12.81 \\
\hline Seawall & $-0.79 * * *$ & 0.03 & $16,867.44 * * *$ & 540.98 \\
\hline Subsidies & $0.02 * * *$ & $7.6 \mathrm{E}-04$ & $443.05^{* * *}$ & 13.72 \\
\hline Donation & $7.2 \mathrm{E}-05^{* * *} *$ & $3.2 \mathrm{E}-06$ & & \\
\hline Tau & 0.02 & 0.04 & -0.54 & 0.03 \\
\hline Gamma & -30.65 & 81.91 & 0 & (Constraint) \\
\hline $\mathrm{N}$ & 179,904 & & 179,904 & \\
\hline Log likelihood & $-42,222.365$ & & $-42,862.253$ & \\
\hline McFadden's $R$-squared & 0.27 & & 0.26 & \\
\hline
\end{tabular}

$* * * p<0.001$ 


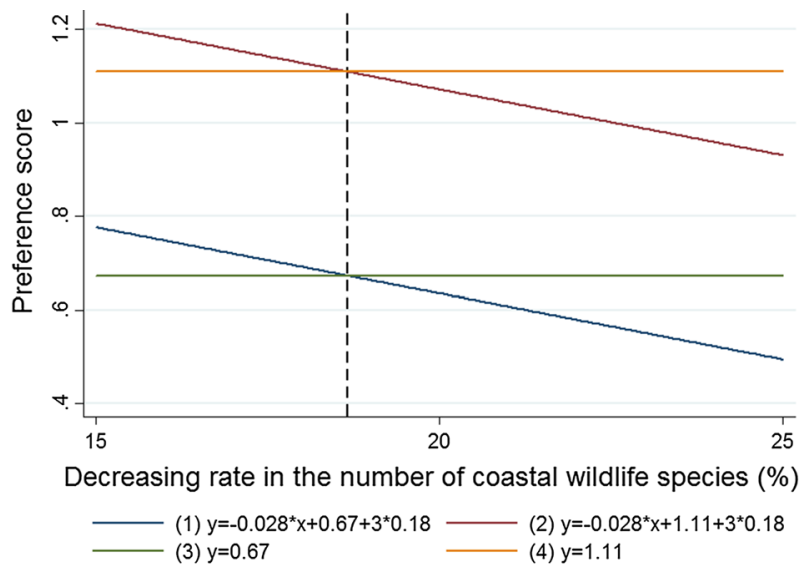

Fig. 2 Relationship between preference score (PS) and Species under the condition where Seawall is $3 \mathrm{~m}$, Donation is 0 JPY, Subsidies is $0 \%$, and Services is $0 \%$. Note: The acceptable loss, which is equivalent to the value of the decreasing rate in the number of coastal wildlife species (\%) (i.e., species) where line (1) crosses line (3) or line (2) crosses line (4), respectively. In either case, acceptable loss becomes the same value: $18.7 \%$. Note that line (1) and (2) are specific cases of Eq. (2). Lines (3) and (4) represent the PS of the scenario where nothing changes, corresponding to lines (1) and (2), respectively

twice as large as those of ASC1 in both Models 1 and 2 (Table 2). This indicates that respondents of the present survey tended to prefer scenario in the middle position on the questionnaire. Species, Services, Seawall, and Subsidies had significantly positive effects, while Donation had a significantly negative effect on the probability of a respondent choosing a particular scenario (Model 1 of Table 2).

We calculated the PS under a condition in which Seawall is 3 and Subsidies, Donation, and Services are each 0 using the coefficients in Model 1 of Table 2 (see Fig. 2). The scenario that increased Species more than $18.7 \%$ was not preferred more than the scenario in which nothing changed (Fig. 2). The acceptable loss of coastal wildlife species under the condition in which Seawall is 3 and Subsidies, Donation, and Services are each 0 is $18.7 \%$. We also calculated marginal WTP for species loss and found a value of 680.95 $\mathrm{JPY} /$ percent in the number of species/capita (Model 2 of Table 2).

\subsection{Effects of individual characteristics}

Table 3 represents the extraction of estimation result of the characteristics combined model. All result of estimation of the characteristics combined model is represented in Table 8 in the "Appendix". The frequency of visiting the sea was significantly and positively correlated with Species, Services, and Donation; negatively correlated with Seawall; and not significantly correlated with Subsidies (Table 3). The previous experiences of a respondent suffering damage from coastal disasters were not significantly correlated with Seawall and Subsidies (Table 3). Respondents' recognition of the possibility of facing damages from coastal disasters was significantly and positively correlated with Seawall, but not with Subsidies (Table 3). Respondents' trust in scientific information about ecosystem degradation was significantly and positively correlated with Species and Services (Table 3 ). Their trust about earthquakes and climate change was significantly and positively correlated with Subsidies, but not with Seawall (Table 3). 
Table 3 Extraction of the estimation of the characteristics combined model

\begin{tabular}{|c|c|c|}
\hline Variables & Coefficient & SE \\
\hline \multicolumn{3}{|l|}{ Scenario attributes } \\
\hline$A S C 1$ & $0.06^{*}$ & 0.02 \\
\hline$A S C 2$ & $0.36 * * *$ & 0.02 \\
\hline Species & $-7.8 \mathrm{E}-03 * * *$ & $1.1 \mathrm{E}-03$ \\
\hline Services & $-2.5 \mathrm{E}-03^{*}$ & $1.0 \mathrm{E}-03$ \\
\hline Seawall & $0.14 * *$ & 0.05 \\
\hline Subsidies & $-2.2 \mathrm{E}-03$ & $1.2 \mathrm{E}-03$ \\
\hline Donation & $-3.1 \mathrm{E}-05^{* * *}$ & $2.7 \mathrm{E}-06$ \\
\hline \multicolumn{3}{|l|}{ Visit sea $\times$ scenario attributes } \\
\hline Visit sea $\times$ Species & $6.1 \mathrm{E}-04 * * *$ & $1.4 \mathrm{E}-04$ \\
\hline Visit sea $\times$ Services & $4.7 \mathrm{E}-04 * * *$ & $1.2 \mathrm{E}-04$ \\
\hline Visit sea $\times$ Seawall & $-0.02 * * *$ & $5.5 \mathrm{E}-03$ \\
\hline Visit sea $\times$ Subsidies & $8.9 \mathrm{E}-05$ & $1.3 \mathrm{E}-04$ \\
\hline Visit sea $\times$ Donation & $1.5 \mathrm{E}-06 * * *$ & $3.1 \mathrm{E}-07$ \\
\hline \multicolumn{3}{|l|}{ Disaster damage $\times$ scenario attributes } \\
\hline Past disaster damage $\times$ Seawall & -0.01 & 0.01 \\
\hline Past disaster damage $\times$ Subsidies & $-2.7 \mathrm{E}-04$ & $2.7 \mathrm{E}-04$ \\
\hline Potential disaster damage $\times$ Seawall & $0.04 * * *$ & $7.6 \mathrm{E}-03$ \\
\hline Potential disaster damage $\times$ Subsidies & $-1.4 \mathrm{E}-04$ & $1.8 \mathrm{E}-04$ \\
\hline \multicolumn{3}{|c|}{ Trust for science information $\times$ scenario attributes } \\
\hline Trust ecosystem degradation $\times$ Species & $5.4 \mathrm{E}-03 * * *$ & $2.2 \mathrm{E}-04$ \\
\hline Trust ecosystem degradation $\times$ Services & $1.9 \mathrm{E}-03 * * *$ & $2.1 \mathrm{E}-04$ \\
\hline Trust ecosystem degradation $\times$ Donation & $-1.1 \mathrm{E}-06$ & $5.7 \mathrm{E}-07$ \\
\hline Trust climate change $\times$ Seawall & -0.01 & $7.5 \mathrm{E}-03$ \\
\hline Trust climate change $\times$ Subsidies & $7.0 \mathrm{E}-04^{* * *}$ & $1.8 \mathrm{E}-04$ \\
\hline Trust potential earthquake $\times$ Seawall & 0.01 & $9.0 \mathrm{E}-03$ \\
\hline Trust potential earthquake $\times$ Subsidies & $1.4 \mathrm{E}-03 * * *$ & $2.1 \mathrm{E}-04$ \\
\hline \multicolumn{3}{|l|}{ (Other variables are omitted) } \\
\hline $\mathrm{N}$ & 179,904 & \\
\hline Log likelihood & $-51,837.853$ & \\
\hline McFadden's $R$-squared & 0.11 & \\
\hline
\end{tabular}

$* p<0.05 ; * * p<0.01 ; * * * p<0.001$

\subsection{WTM}

Respondent's previous experience of suffering damage from coastal disasters was significantly and positively correlated with the probability that WTM is "yes" (Table 4). Respondent's risk preference was significantly and negatively correlated with the probability that WTM is "yes" (Table 4). Respondents' trust in scientific information about earthquakes and climate change was significantly and positively correlated with the probability that WTM is "yes" (Table 4). The absolute value of Z value (a value obtained by dividing a coefficient by a standard error of the parameter) was largest in respondent's trust in scientific information about earthquake, followed by respondent's trust for 
Table 4 Results of random-effects ordered logistic regression

\begin{tabular}{|c|c|c|c|}
\hline Variables & Coefficient & SE & $Z$ value \\
\hline Constant & 0.02 & 0.01 & 1.51 \\
\hline Species & $6.8 \mathrm{E}-03 * * *$ & $2.4 \mathrm{E}-04$ & 27.89 \\
\hline Services & $3.1 \mathrm{E}-03 * * *$ & $2.1 \mathrm{E}-04$ & 14.65 \\
\hline Seawall & -0.02 & $8.7 \mathrm{E}-03$ & -1.78 \\
\hline Subsidies & $0.01 * * *$ & $2.2 \mathrm{E}-04$ & 45.95 \\
\hline Donation & $-9.7 \mathrm{E}-06^{* * * *}$ & $4.5 \mathrm{E}-07$ & -21.46 \\
\hline Visit sea & 0.02 & 0.02 & 0.96 \\
\hline Past disaster damage & $0.13 *$ & 0.06 & 2.50 \\
\hline Potential disaster damage & 0.06 & 0.04 & 1.69 \\
\hline Risk preference & $-0.03 *$ & 0.02 & -2.28 \\
\hline Trust ecosystem degradation & $0.14 *$ & 0.05 & 2.58 \\
\hline Trust climate change & $0.11 * *$ & 0.04 & 2.82 \\
\hline Trust potential earthquake & $0.27 * * *$ & 0.05 & 5.84 \\
\hline Gender & $-0.30 * * *$ & 0.07 & -4.00 \\
\hline Age & $5.9 \mathrm{E}-03$ & $3.5 \mathrm{E}-03$ & 1.71 \\
\hline Income & $8.4 \mathrm{E}-03$ & 0.02 & 0.52 \\
\hline Children & 0.12 & 0.07 & 1.58 \\
\hline House & $-0.43 * * *$ & 0.08 & -5.07 \\
\hline Understanding & $0.12 * *$ & 0.04 & 3.00 \\
\hline Cut1 & -0.23 & 0.26 & -0.91 \\
\hline Cut 2 & 3.96 & 0.26 & 15.39 \\
\hline Number of observation & 119,936 & & \\
\hline Log likelihood & $-82,138.677$ & & \\
\hline McFadden's $R$-squared & 0.31 & & \\
\hline
\end{tabular}

$* p<0.05 ; * * p<0.01 ; * * * p<0.001$

scientific information about climate change, respondent's previous experience of suffering damage from coastal disasters, and respondent's risk preference (Table 4).

\section{Discussion and conclusions}

Our respondents preferred high seawalls rather than low seawalls (Model 1 of Table 2). High seawalls can reduce coastal disaster risks, but they have negative aspects (i.e., ecosystem degradation and view deterioration). Because our questionnaire did not explain the negative aspects to respondents, our respondents might only consider seawalls' function of reducing disaster risks. If the questionnaire had explained the negative aspects of raising seawall heights, respondents' preferences for higher seawalls may have decreased.

The acceptable loss of coastal wildlife species numbers under the condition in which Seawall is three meters and other attributes are 0 was $18.7 \%$ (Fig. 2). In this condition, public preference for higher seawalls is maximized and public preference for degradation of ecosystem services is minimized. In other words, the acceptable loss in Fig. 2 represents the maximum acceptable loss when raising seawall heights. In addition, as mentioned above, public preferences for higher seawalls in Model 1 of Table 2 might fall. If civil 
preference for higher seawalls is lower than the value in Model 1 of Table 2, the acceptable loss of species is also lower than the value given in Fig. 2. This result indicated that our respondents did not prefer seawall heights to be raised at all unless the resulting negative effects on coastal ecosystems were reduced.

People who visit coastal areas preferred ecosystem conservation and did not prefer seawall height increases (Table 3). On the other hand, people who recognize the possibility of suffering damages from coastal disasters preferred higher seawalls, although they did not prefer increasing subsidies for moving to disaster-free areas (Table 3). Public recognition of potentially suffering damage themselves as a result of coastal disasters did not correlated with the probability that WTM is "yes" (Table 4). These results indicated that people who recognize their personal potential to suffer damages regarded higher seawalls as a reasonable countermeasure rather than increasing subsidies for moving to safer areas. The results also indicated a conflict between people who visit coastal areas and people living near coastal areas. Reducing negative effects to coastal ecosystems as a result of seawall construction might be one method to solve this conflict.

People who trust scientific information about biodiversity degradation preferred ecosystem conservation (Table 3). This result was similar to previous studies on climate change, such as Akter et al. (2012). People who trust scientific information about climate change and earthquakes preferred increasing subsidies to move to safer areas (Table 3), and trust in scientific information positively affected the probability that WTM is "yes" (Table 4). Though people who recognize their potential to suffer damages from coastal disasters regarded raising seawall heights as a reasonable countermeasure compared to increasing subsidies to move to safer areas, if these same people trust scientific information about climate change or earthquakes, increasing subsidies for moving to safer areas could be regarded as another reasonable countermeasure. In addition, the effect of public trust in earthquake information on WTM was larger than the effect of trust in climate change (Table 3). We inferred that this is because the effect of earthquakes is well known to many people compared to the effect of climate change due to previous earthquakes, such as the 2011 Tohoku earthquake.

Our study indicated that coastal citizens did not prefer the excessive degradation of ecosystems due to constructing costal structures, whereas they preferred construction to move to other areas as a means of coastal disaster risk reduction. Therefore, it is necessary to reduce negative effects to coastal ecosystems due to seawall construction. Implementing Eco-DRR (Estrella and Saalismaa 2012) and a combination of hard and natural defenses (Estrella and Saalismaa 2012) could be another solution. In addition, our study indicated the influences of public trust in scientific information about ecosystem degradation, climate change, and earthquakes. Increasing public trust in scientific information increased preferences for ecosystem conservation and disaster risk reduction. In particular, increasing public trust in scientific information about climate change and earthquakes may change popular preferences of disaster risk-reduction methods from raising seawall heights to moving to a new location. The change was higher for earthquakes than for climate change. Thus, this study indicates the possibility of implementing Eco-DRR in Japanese coastal areas and the social effect of increasing public trust in scientific information.

Acknowledgments This work was conducted under the Program for Risk Information on Climate Change (SOUSEI Program) supported by the Ministry of Education, Culture, Sports, Science, and TechnologyJapan (MEXT) and Grant-in-Aid for Specially Promoted Research > (26000001) by the Japan Society for the Promotion of Science. 
Open Access This article is distributed under the terms of the Creative Commons Attribution 4.0 International License (http://creativecommons.org/licenses/by/4.0/), which permits unrestricted use, distribution, and reproduction in any medium, provided you give appropriate credit to the original author(s) and the source, provide a link to the Creative Commons license, and indicate if changes were made.

\section{Appendix}

See Tables 5, 6, 7, 8 .

Table 5 Abstract of our respondents

\begin{tabular}{ll}
\hline Individual characteristics & Proportion (\%) \\
\hline Gender & \\
Man & 55.36 \\
Woman & 44.64 \\
Age & \\
20 s & 5.84 \\
30 s & 19.84 \\
40 s & 30.95 \\
50 s & 26.73 \\
60 s & 16.64 \\
Children & \\
I have children & 56.74 \\
I do not have children & 43.26 \\
House & \\
I have my own house & 71.54 \\
I do not have my own house (apartment, etc.) & 28.46 \\
Income & \\
Under 3 million JPY & 42.86 \\
Over 3 million JPY and under 5 million JPY & 21.28 \\
Over 5 million JPY and under 7.5 million JPY & 17.73 \\
Over 7.5 million JPY and under 10 million JPY & 11.18 \\
Over 10 million JPY and under 15 million JPY & 5.38 \\
Over 15 million JPY & 1.57 \\
$N$ & 7496 \\
\hline
\end{tabular}

Table 6 Question items regarding individual attributes, levels for each question item, and proportion of each level in respondent's answer

Individual characteristics

Proportion (\%)

Trust for scientific information about degradation of species

Trust very much

Trust to some extent

55.66

Neither trust nor do not trust

22.75

Do not trust so much

3.03 
Table 6 continued

\begin{tabular}{ll}
\hline Individual characteristics & Proportion (\%)
\end{tabular}

Do not trust at all

Trust for scientific information about climate change

Trust very much

Trust to some extent

Neither trust nor do not trust

Do not trust so much

Do not trust at all

Trust for scientific information about great earthquake

Trust very much

Trust to some extent

Neither trust nor do not trust

Do not trust so much

Do not trust at all

Past damage by high tide or tsunami

Total collapse of house

Partial destruction of house, inundation above floor level

Inundation under floor level

Small damages less than under inundation under floor level

No damage

91.45

Recognition for possibility that a respondent is damaged by high tide or tsunami in future

The possibility is very high

The possibility is relative high

The possibility is relative low

The possibility is very low

45.44

Frequency that a respondent goes to sea

More than once a month

Once a month

Once in 3 months

Once in a half year

Once in a year

Once in several years

I have never been to the sea

1.95

Risk preference: a precipitation percentage that a respondent takes an umbrella with when going out I always take an umbrella (0\%) 8.36

$10 \%$

1.68

$20 \%$

$30 \%$

$40 \%$

16.74

$50 \%$

24.24

$60 \%$

$70 \%$

$80 \%$

$90 \%$

1.37 
Table 6 continued

\begin{tabular}{ll}
\hline Individual characteristics & Proportion (\%) \\
\hline I always do not take an umbrella $(100 \%)$ & 3.00 \\
Understanding for questionnaire & \\
Understand very much & 10.39 \\
Understand to some extent & 50.88 \\
Neither understand nor do not understand & 21.80 \\
Do not understand so much & 15.33 \\
Do not understand at all & 1.60 \\
$N$ & 7496 \\
\hline
\end{tabular}

Table 7 Abstract of variables used in our analysis

Variable names Description

Scenario attributes

ASC1 Left alternative-specific constant (dummy variable)

ASC2 Center alternative-specific constant (dummy variable)

Species Loss of number of species of coastal wildlife

Services Loss of monetary benefits from coastal ecosystem services

Seawall Raising height of seawall

Subsidies Rate of government subsidies in moving cost

Donations The amount of donation for conserving coastal ecosystem

Individual attributes

Trust Degree of a respondent's trust for science information about degradation of species.

ecosystem

degradation

Trust climate Degree of a respondent's trust for science information about climate change (level 0-4) change

Trust potential Degree of a respondent's trust for science information about great earthquake (level 0-4) earthquake

Past disaster Degree of a respondent's past damage by high tide or tsunami (level 0-4)

damage

Potential

disaster

damage

Visit sea

Degree of a respondent's recognition for possibility that a respondent is damaged by high tide or tsunami in future (level $0-3$ )

Risk preference Probability of precipitation that a respondent goes out with having umbrella (level 0-10)

Gender

A respondent's sex $($ male $=0$, female $=1)$

Age

A respondent's age (years)

Income

A respondent's annual income (level 0-5)

Children

Presence of children in a respondent's household (dummy variable)

House Whether a respondent's house is his own house or not (dummy variable)

Understanding Degree of a respondent's understanding for questionnaire contents (level 0-4) 
Table 8 Full model of the characteristics combined model

\begin{tabular}{|c|c|c|}
\hline Variables & Coefficient & SE \\
\hline \multicolumn{3}{|l|}{ Scenario attributes } \\
\hline$A S C 1$ & $0.06 *$ & 0.02 \\
\hline$A S C 2$ & $0.36 * * *$ & 0.02 \\
\hline Species & $-7.8 \mathrm{E}-03 * * *$ & $1.1 \mathrm{E}-03$ \\
\hline Services & $-2.5 \mathrm{E}-03^{*}$ & $1.0 \mathrm{E}-03$ \\
\hline Seawall & $0.14 * *$ & 0.05 \\
\hline Subsidies & $-2.2 \mathrm{E}-03$ & $1.2 \mathrm{E}-03$ \\
\hline Donation & $-3.1 \mathrm{E}-05^{* * *}$ & $2.7 \mathrm{E}-06$ \\
\hline \multicolumn{3}{|l|}{ Visit sea $\times$ scenario attributes } \\
\hline Visit sea $\times$ Species & $6.1 \mathrm{E}-04 * * *$ & $1.4 \mathrm{E}-04$ \\
\hline Visit sea $\times$ Services & $4.7 \mathrm{E}-04 * * *$ & $1.2 \mathrm{E}-04$ \\
\hline Visit sea $\times$ Seawall & $-0.02 * * *$ & $5.5 \mathrm{E}-03$ \\
\hline Visit sea $\times$ Subsidies & $8.9 \mathrm{E}-05$ & $1.3 \mathrm{E}-04$ \\
\hline Visit sea $\times$ Donation & $1.5 \mathrm{E}-06 * * *$ & $3.1 \mathrm{E}-07$ \\
\hline \multicolumn{3}{|l|}{ Disaster damage $\times$ scenario attributes } \\
\hline Past disaster damage $\times$ Seawall & -0.01 & 0.01 \\
\hline Past disaster damage $\times$ Subsidies & $-2.7 \mathrm{E}-04$ & $2.7 \mathrm{E}-04$ \\
\hline Potential disaster damage $\times$ Seawall & $0.04 * * *$ & $7.6 \mathrm{E}-03$ \\
\hline Potential disaster damage $\times$ Subsidies & $-1.4 \mathrm{E}-04$ & $1.8 \mathrm{E}-04$ \\
\hline \multicolumn{3}{|c|}{ Trust for science information $\times$ scenario attributes } \\
\hline Trust ecosystem degradation $\times$ Species & $5.4 \mathrm{E}-03 * * *$ & $2.2 \mathrm{E}-04$ \\
\hline Trust ecosystem degradation $\times$ Services & $1.9 \mathrm{E}-03 * * *$ & $2.1 \mathrm{E}-04$ \\
\hline Trust ecosystem degradation $\times$ Donation & $-1.1 \mathrm{E}-06$ & $5.7 \mathrm{E}-07$ \\
\hline Trust climate change $\times$ Seawall & -0.01 & $7.5 \mathrm{E}-03$ \\
\hline Trust climate change $\times$ Subsidies & $7.0 \mathrm{E}-04 * * *$ & $1.8 \mathrm{E}-04$ \\
\hline Trust potential earthquake $\times$ Seawall & 0.01 & $9.0 \mathrm{E}-03$ \\
\hline Trust potential earthquake $\times$ Subsidies & $1.4 \mathrm{E}-03 * * *$ & $2.1 \mathrm{E}-04$ \\
\hline \multicolumn{3}{|l|}{ Risk preference $\times$ scenario attributes } \\
\hline Risk preference $\times$ Seawall & $-3.4 \mathrm{E}-03$ & $3.1 \mathrm{E}-03$ \\
\hline Risk preferences $\times$ Subsidies & $-2.3 \mathrm{E}-05$ & $7.2 \mathrm{E}-05$ \\
\hline \multicolumn{3}{|l|}{ Socioeconomic attributes $\times$ scenario attributes } \\
\hline Gender $\times$ Species & $-2.0 \mathrm{E}-03 * * *$ & $4.2 \mathrm{E}-04$ \\
\hline Gender $\times$ Services & $-2.4 \mathrm{E}-03 * * *$ & $3.9 \mathrm{E}-04$ \\
\hline Gender $\times$ Seawall & $-0.04 *$ & 0.02 \\
\hline Gender $\times$ Subsidies & $-2.7 \mathrm{E}-03 * * *$ & $4.0 \mathrm{E}-04$ \\
\hline Gender $\times$ Donation & $2.3 \mathrm{E}-06^{*}$ & $1.0 \mathrm{E}-06$ \\
\hline Age $\times$ Species & $5.0 \mathrm{E}-05 * *$ & $1.8 \mathrm{E}-05$ \\
\hline Age $\times$ Services & $2.2 \mathrm{E}-05$ & $1.7 \mathrm{E}-05$ \\
\hline Age $\times$ Seawall & $-1.6 \mathrm{E}-03 *$ & $7.3 \mathrm{E}-04$ \\
\hline Age $\times$ Subsidies & $-2.5 \mathrm{E}-06$ & $1.7 \mathrm{E}-05$ \\
\hline Age $\times$ Donation & $7.6 \mathrm{E}-08$ & $4.3 \mathrm{E}-08$ \\
\hline Income $\times$ Species & $1.2 \mathrm{E}-04$ & $1.5 \mathrm{E}-04$ \\
\hline Income $\times$ Services & $1.5 \mathrm{E}-04$ & $1.4 \mathrm{E}-04$ \\
\hline
\end{tabular}


Table 8 continued

\begin{tabular}{lll}
\hline Variables & Coefficient & SE \\
\hline Income $\times$ Seawall & $-5.6 \mathrm{E}-03$ & $6.2 \mathrm{E}-03$ \\
Income $\times$ Subsidies & $1.5 \mathrm{E}-04$ & $1.5 \mathrm{E}-04$ \\
Income $\times$ Donation & $2.0 \mathrm{E}-06^{* * *}$ & $3.6 \mathrm{E}-07$ \\
Children $\times$ Species & $1.8 \mathrm{E}-04$ & $4.0 \mathrm{E}-04$ \\
Children $\times$ Services & $1.2 \mathrm{E}-04$ & $3.6 \mathrm{E}-04$ \\
Children $\times$ Seawall & 0.01 & 0.02 \\
Children $\times$ Subsidies & $-1.3 \mathrm{E}-04$ & $3.7 \mathrm{E}-04$ \\
Children $\times$ Donation & $-9.6 \mathrm{E}-07$ & $9.4 \mathrm{E}-07$ \\
House $\times$ Species & $1.6 \mathrm{E}-05$ & $4.5 \mathrm{E}-04$ \\
House $\times$ Services & $3.3 \mathrm{E}-04$ & $4.1 \mathrm{E}-04$ \\
House $\times$ Seawall & 0.02 & 0.02 \\
House $\times$ Subsidies & $2.5 \mathrm{E}-04$ & $4.2 \mathrm{E}-04$ \\
House $\times$ Donation & $3.4 \mathrm{E}-08$ & $1.1 \mathrm{E}-06$ \\
Understand questionnaire $\times$ scenario attributes & & \\
Understanding $\times$ Species & $1.6 \mathrm{E}-03 * * *$ & $2.0 \mathrm{E}-04$ \\
Understanding $\times$ Services & $1.1 \mathrm{E}-03^{* * *}$ & $1.9 \mathrm{E}-04$ \\
Understanding $\times$ Seawall & $0.03^{* *}$ & $8.2 \mathrm{E}-03$ \\
Understanding $\times$ Subsidies & $8.3 \mathrm{E}-04 * * *$ & $1.9 \mathrm{E}-04$ \\
Understanding $\times$ Donation & $-4.5 \mathrm{E}-07$ & $4.8 \mathrm{E}-07$ \\
$\mathrm{~N}$ & 179,904 & \\
Log likelihood & $-51,837.853$ & \\
McFadden's $R$-squared & 0.11 & \\
\hline & &
\end{tabular}

$* p<0.05 ; * * p<0.01 ; * * * p<0.001$

\section{References}

Akter S, Bennett J (2011) Household perceptions of climate change and preferences for mitigation action: the case of the Carbon Pollution Reduction Scheme in Australia. Clim Change 109:416-436

Akter S, Bennett J, Ward MB (2012) Climate change scepticism and public support for mitigation: evidence from an Australian choice experiment. Global Environ Change 22:736-745

Cameron TA (2005) Individual option prices for climate change mitigation. J Public Econ 89:283-301

Carson RT, Louviere JJ, Wei E (2010) Alternative Australian climate change mitigation plans: public's views. Energy Policy 38:902-911

Dolidon N, Hofer T, Jansky L, Sidle R (2009) Watershed and forest management for landslide risk reduction. In: Sassa K, Canuti P (eds) Landslides, disaster risk reduction. Springer, Berlin, pp 633-646

Dugan JE, Hubbard DM, Rodil IF, Revell DL, Schroeter S (2008) Ecological effects of coastal armoring on sandy beaches. Mar Ecol Evol Perspect 29:160-170

Earthquake Research Committee (2014) http://www.jishin.go.jp/main/index-e.html. Accessed 20 May 2015

Estrella M, Saalismaa N (2012) The role of ecosystem management for disaster risk reduction. In: Gupta AK, Nair SS (eds) Ecosystem approach to disaster risk reduction. National Institute of Disaster Management, India, pp 5-44

Fiebig DG, Keane MP, Louviere J, Wasi N (2010) The generalized multinomial logit model: accounting for scale and coefficient heterogeneity. Market Sci 29:393-421

Gonzalez P, Marques A (2008) Forest carbon sequestration from avoided deforestation and reforestation in Mata Atlântica (Atlantic Forest), Sul da Bahia, Brazil. Nature conservancy, Arlington, VA, USA

Government of Sri Lanka, Disaster Management Centre (2005) Towards a safer Sri Lanka: road map for disaster risk management. http://www.adrc.asia/documents/dm_information/srilanka_plan02.pdf. Accessed 20 May 2015 
Government of Sri Lanka, United Nations Development Programme, United Nations Environmental Programme (2011) Integrated strategic environmental assessment in the Northern Province. Colombo, UNDP Sri Lanka

Granek EF, Ruttenberg BI (2007) Protective capacity of mangroves during tropical storms: a case study from 'Wilma' and 'Gamma' in Belize. Mar Ecol Prog Ser 343:101-105

Greene W, Hensher D (2010) Does scale heterogeneity across individual matter? An empirical assessment of alternative logit models. Transportation 37:413-428

Gu Y, Hole AR, Knox S (2013) Fitting the multinomial logit model in Stata. Stata J 13(2):382-397

Gupta AK, Nair SS (2012) Understanding eco-DRR: Introduction to the Book. In: Gupta AK, Nair SS (eds) Ecosystem approach to disaster risk reduction. National Institute of Disaster Management, India, pp $1-4$

Hanley N, Barbier EB (2009) Pricing nature: cost-benefit analysis and environmental policy. Eur Rev Agric Econ 37:579-581

Hole AR, Kolstad JR (2012) Mixed logit estimation of willingness to pay distributions: a comparison of models in preference space and WTP space using data from a health-related choice experiment. Empir Econ 42:445-469

Lee JJ, Cameron TA (2008) Popular support for climate change mitigation: evidence from a general population mail survey. Environ Resource Econ 41:223-248

Lindsay BE, Halstead JM, Tupper HC, Vaske JJ (1992) Factors influencing the willingness to pay for coastal beach protection. Coast Manag 20:291-302

Millennium Ecosystem Assessment (2005) Ecosystems and human well-being: current state and trends. Findings of the Condition and Trends Working Group

Mori N, Yasuda T, Mase H, Tom T, Oku Y (2010) Projection of extreme wave climate change under global warming. Hydrol Res Lett 4:15-19

Murakami K, Agatsuma S, Nakamura A (2013) Ecosystem structure succession in seaside park pond associated with tsunami. J Jpn Soc Civil Eng 69(2):19-24

Nakashizuka T (2013) Short- and Long-term ecosystem monitoring after the Great East Japan Earthquake. Chikyu Kankyo 18(1):63-67

Poortinga W, Spence A, Whitmarsh L, Capstick S, Pidgeon NF (2011) Uncertain climate: an investigation into public scepticism about anthropogenic climate change. Glob Environ Change 21:1015-1024

Scarpa R, Thiene M, Train K (2008) Utility in willingness to pay space: a tool to address confounding random scale effects in destination choice to Alps. Am J Agric Econ 90:994-1010

Shoyama K, Managi S, Yamagata Y (2013) Public preferences for biodiversity conservation and climate change mitigation: a choice experiment using ecosystem services indicators. Land Use Policy 34:282-293

Sonnier G, Ainslie A, Otter T (2007) Heterogeneity distributions of willingness-to-pay in choice models. Quant Market Econ 5:313-331

The Nature Conservation Society of Japan (NACS-J) (2013) http://www.nacsj.or.jp/katsudo/kaiho/pdf/ No534-p2-3.pdf. Accessed 20 May 2015

Thiene M, Scarpa R (2009) Deriving and testing efficient estimates of WTP distributions in destination choice models. Environ Resour Econ 44:379-395

Toft J (2005) Benthic Macroinvertebrate monitoring of Seahurst Park 2004, Pre-construction of seawall removal. University of Washington School of Aquatic and Fishery Sciences, Washington, USA, p 15

Train KB (2009) Discrete choice methods with simulation, 2nd edn. Cambridge University Press, Cambridge

Train KE, Weeks M (2005) Discrete choice models in preference space and willingness-to-pay space. In: Scarpa R, Alberini A (eds) Application of simulation methods in environmental and resource economics. Springer, Dordrecht, pp 1-16

Tsurumi T, Managi S (2015) Environmental value of greenspaces in Japan: an application of the life satisfaction approach. Ecol Econ 120:1-12

Urabe J, Suzuki T, Makino W (2013) Immediate ecological impacts of the 2011 Tohoku Earthquake Tsunami on intertidal flat communities. PLoS ONE 8(5):e62779

Viscusi WK, Zeckhauser RJ (2006) The perception and valuation of the risks of climate change: a rational and behavioral blend. Clim Change 77:151-177

Yasuda T, Nakajo S, Kim SY, Mase H, Mori N, Horsburgh K (2014) Evaluation of future storm surge risk in East Asia based on state-of-the-art climate change projection. Coast Eng 83:65-71 